\title{
Syntheses, Experimental and Theoretical Studies on Absorption/Emission Properties of Pyrazoline-Containing Aryl/Methoxynaphthyl Substituents
}

\author{
Jorge Trilleras, ${ }^{*, a}$ Edwin González-López, ${ }^{a}$ Jhair León-Jaramillo, ${ }^{a}$ \\ Alfredo Pérez-Gamboa, ${ }^{a}$ Esneyder Puello-Polo, ${ }^{b}$ Pablo Romo, ${ }^{c}$ \\ Alejandro Ortiz $z^{c, d}$ and Jairo Quiroga ${ }^{c, d}$ \\ ${ }^{a}$ Grupo/Semillero de Investigación en Compuestos Heterocíclicos, Programa de Química-Ciencias Básicas, \\ Universidad del Atlántico, km 7 Via Puerto, Atlántico, Colombia \\ ${ }^{b}$ Grupo de Investigación en Oxi/Hidrotratamiento Catalítico y Nuevos Materiales, \\ Programa de Química-Ciencias Básicas, Universidad del Atlántico, km 7 Via Puerto, Atlántico, Colombia \\ ${ }^{c}$ Grupo de Investigación de Compuestos Heterocíclicos, Departamento de Química, \\ Universidad del Valle, A. A. 25360 Cali, Colombia \\ ${ }^{d}$ Centre for Bioinformatics and Photonics, CIBioFI, \\ Calle 13 No. 100-00, Edificio 320, No. 1069, 760032 Cali, Colombia
}

\begin{abstract}
5-Aryl-3-(2-methoxynaphthalen-6-yl)-1-phenylpyrazoline derivatives were synthesized starting from (E)-1-(3-aryl)-(2-methoxynaphthalen-6-yl)-prop-2-en-1-one and phenylhydrazine. The compounds were characterized by ${ }^{1} \mathrm{H}$ and ${ }^{13} \mathrm{C}$ nuclear magnetic resonance (NMR), elemental analyses and mass spectrometry. Some compounds showed promising luminescence properties in solution and in solid state; the absorption and emission characteristics were measured and the fluorescence quantum yield of two of the derivatives [4,5-dihydro-3-(2-methoxynaphthalen6-yl)-5-(3,4,5-trimethoxyphenyl)-1-phenyl-1 $H$-pyrazoline and 5-(4-chlorophenyl)-4,5-dihydro3-(2-methoxynaphthalen-6-yl)-1-phenyl-1H-pyrazoline] were found to have excellent values compared to rhodamine B standard. Theoretical calculations at time-dependent density functional theory (TD-DFT) level are in agreement with the experimental measurements and are helpful to explain the electronic behavior.
\end{abstract}

Keywords: luminescence, 1-naphthalenylpropenone, TD-DFT, triaryl pyrazoline derivatives

\section{Introduction}

The properties and applications of pyrazoline and their analogues are numerous and known, not only in the biological and medical field, ${ }^{1-4}$ but also for their potential and practical applications as materials with luminescent and nonlinear optical properties..$^{5-8}$

The building of these $N$-heterocycles systems, from simple reactions, using small molecules and compatible with multicomponent, regioselective, eco-friendly and efficient synthetic procedures, which include variations to conventional methods, allows to incorporate specific structural characteristics. ${ }^{9-14}$

Substituents of different nature, electron withdrawing group (EWG) and electron releasing group (ERG), in aromatic aldehydes, ketones and hydrazines, make them

*e-mail: jorgetrilleras@mail.uniatlantico.edu.co versatile synthetic auxiliaries in classical organic synthesis. Reports in the literature ${ }^{15-18}$ have attributed an increase in the biological properties of pyrazoline derivatives to the combined effect of ERG, aryl substituents and $\pi$-extended configuration. These electronic and structural characteristics of compounds containing the pyrazole nucleus are also widely used in electroluminescence fields. Reports in the literature include studies on solvatochromic effect and electrochemical, photophysical, optical and nonlinear optical properties. ${ }^{5-8,19-22}$ Following our research on the synthesis and evaluation of potential applications of pyrazole derivatives, ${ }^{23,24}$ and the growing interest in the development of luminescence small molecules as emitting materials and biology research, ${ }^{5-8,19-25}$ we report a series of pyrazoline derivatives incorporating methoxyl, an electron donor group, naphthyl and phenyl substituents as chromophores, on the $\pi$-conjugated structure and analysis of absorption/emission properties of these compounds. 


\section{Results and Discussion}

\section{Synthesis and characterization of the chalcones $\mathbf{3}$ and pyrazoline 4 derivatives}

Pyrazoline derivatives were obtained by a conventional method, outlined in Scheme 1. Chalcones 3 were prepared by the classical method of Claisen-Schmidt condensation between 1-(2-methoxynaphthalen-6-yl) ethanone and aromatic aldehydes. ${ }^{26}$ The ultrasoundpromoted reaction, unlike conventional heating, results in improved yields, shorter reaction times, easy work-up and milder conditions, compared with data reported in the literature for chalcones $\mathbf{3 a}, \mathbf{3 b}$ and $\mathbf{3 g}$. $^{27}$

Due to the availability of commercial reagents (aldehydes and ketones), and different types of reactions involved, the $\alpha, \beta$-unsaturated derivatives are versatile precursors for the construction of substituted heterocyclic. Specifically, in the incorporation of ERG and core recognized as chromophores-a 2-methoxynaphthalen-6-yl group in the 3-position and 5-aryl pyrazoline moiety, both linked from the starting chalcone $3{ }^{28}$ The preparation of the pyrazoline derivatives $\mathbf{4 a - g}$ was made using Michael cyclocondensation reaction. By varying the reaction parameters (solvent, acid and molar ratio of reactants), the reaction conditions suitable were established to prepare the pyrazoline derivatives in less time and higher yield. An acetic acid/water mixture allows visualizing the progress of the reaction and easy isolation of the solid formed. The results inducing the reaction by ultrasound radiation were not satisfactory. In the molecular structure of derivatives 4, it is remarkable the presence of a cyclic hydrazine core, although this phenomenon diminishes the electronic conjugation respect to derivatives $\mathbf{3}$, the mentioned fact does not allow the isomerization of the double bond $\mathrm{C}=\mathrm{N}$. This feature allows favored processes of photoinduced electronic transfer (PET) and so a strong influence in the luminescent properties ${ }^{29-31}$ as this behavior can be seen in the computational detail below.

The yields (see Table 1) of compounds $\mathbf{3}$ and $\mathbf{4}$ were determined by stoichiometric analysis of the starting materials and the final weight of product obtained after purified and complete drying (compared to the stoichiometric expected quantity). Despite the difference in electronegativity of the substituents on chalcone and pyrazoline derivatives, no influence was observed on the final yield of the compounds.

All compounds were characterized by nuclear magnetic resonance (NMR), elemental analyses and mass spectrometry (MS) analysis. The ${ }^{1} \mathrm{H}$ NMR spectra of all the derivatives show the characteristic signals. In the case of compounds $\mathbf{3}$, signals are observed in the aromatic region with multiplicity of doublets, corresponding to the $\mathrm{H} \alpha$ and $\mathrm{H} \beta$ protons of the unsaturated system, with $J>15 \mathrm{~Hz}$. The compound $\mathbf{4}$ have two methylene protons $(\mathrm{Ha}$ and $\mathrm{Hb}$ ) and one methine proton $(\mathrm{Hx})$, evidenced in the spectrum by

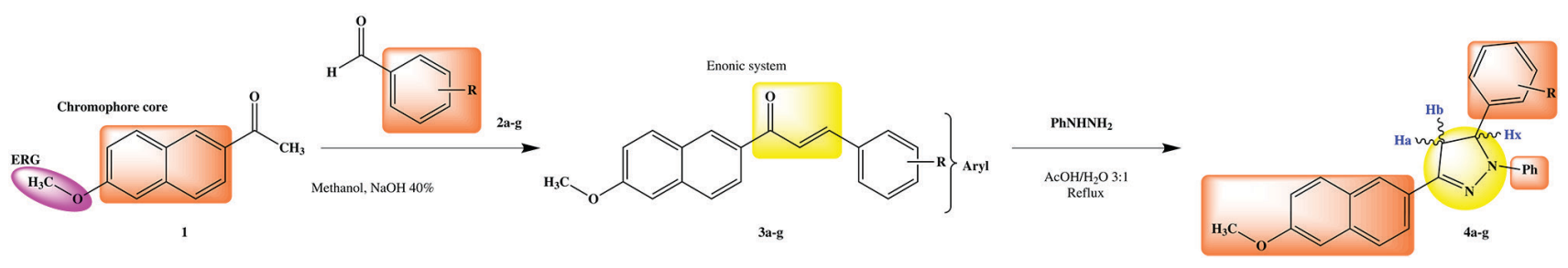

Scheme 1. Reaction sequence for the synthesis of (E)-1-(3-aryl)-(2-methoxynaphthalen-6-yl)-prop-2-en-1-ones (3a-g) and 5-aryl-3-(2-methoxynaphthalen6-yl)-1-phenylpyrazolines (4a-g).

Table 1. Reaction time $\left(\mathrm{t}_{\mathrm{r}}\right)$, melting point $\left(\mathrm{T}_{\mathrm{f}}\right)$ and yield for compounds $\mathbf{3}$ and $\mathbf{4}$

\begin{tabular}{|c|c|c|c|c|c|c|c|}
\hline \multirow{2}{*}{ entry } & \multirow{2}{*}{ Aryl } & \multicolumn{3}{|c|}{ Compound $\mathbf{3}$} & \multicolumn{3}{|c|}{ Compound 4} \\
\hline & & $\mathrm{t}_{\mathrm{r}} / \min$ & $\mathrm{T}_{\mathrm{f}} /{ }^{\circ} \mathrm{C}$ & Yield / \% & $\mathrm{t}_{\mathrm{r}} / \mathrm{h}$ & $\mathrm{T}_{\mathrm{f}} /{ }^{\circ} \mathrm{C}$ & Yield / \% \\
\hline $\mathrm{a}$ & 4- $\mathrm{CH}_{3} \mathrm{C}_{6} \mathrm{H}_{4}$ & 10 & $166-169$ & $80^{\mathrm{a}}$ & 4.5 & $228-231$ & 75 \\
\hline $\mathrm{b}$ & $4-\mathrm{H}_{3} \mathrm{COC}_{6} \mathrm{H}_{4}$ & 5 & $131-134$ & $81^{\mathrm{a}}$ & 3 & $214-217$ & 70 \\
\hline c & $3,4,5-t r i-\mathrm{H}_{3} \mathrm{COC}_{6} \mathrm{H}_{2}$ & 10 & $126-129$ & 78 & 3 & 186-189 & 70 \\
\hline d & $3,4-\mathrm{OCH}_{2} \mathrm{C}_{6} \mathrm{H}_{3}$ & 10 & $170-173$ & 76 & 4 & $238-241$ & 70 \\
\hline $\mathrm{e}$ & $2-\mathrm{H}_{3} \mathrm{COC}_{11} \mathrm{H}_{6}$ & 10 & $210-213$ & 77 & 3.5 & $245-248$ & 70 \\
\hline $\mathrm{f}$ & 4- $\mathrm{ClC}_{6} \mathrm{H}_{4}$ & 5 & $166-169$ & 80 & 3 & $219-222$ & 73 \\
\hline $\mathrm{g}$ & $4-\mathrm{NO}_{2} \mathrm{C}_{6} \mathrm{H}_{4}$ & 15 & $198-201$ & $65^{\mathrm{a}}$ & 3.5 & $222-225$ & 75 \\
\hline
\end{tabular}

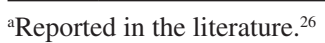


Table 2. Absorption and emission data of compounds $\mathbf{3 c}, \mathbf{3 f}, \mathbf{4 c}$ and $\mathbf{4 f}$

\begin{tabular}{lccccc}
\hline Compound & $\lambda_{1} / \mathrm{nm}$ & $\lambda_{2} / \mathrm{nm}$ & $\lambda_{\text {max }}{ }^{\mathrm{a}} / \mathrm{nm}$ & $\varepsilon /\left(\mathrm{M}^{-1} \mathrm{~cm}^{-1}\right)$ & $1.19 \times 10^{4}$ \\
\hline 3c & 229 & 262 & 317 & $1.66 \times 10^{4}$ & $372\left(6.72 \times 10^{-3}\right)$ \\
3f & 231 & 264 & 319 & $1.39 \times 10^{4}$ & $370\left(1.15 \times 10^{-3}\right)$ \\
4c & 239 & - & 359 & $1.84 \times 10^{4}$ & $449(0.593)$ \\
4f & 239 & - & 361 & $448(0.740)$ \\
\hline
\end{tabular}

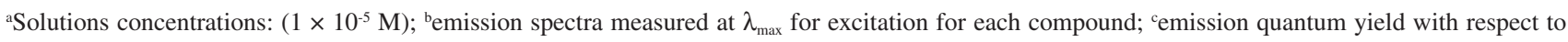
rhodamine B as standard.

three doublets of doublets corresponding to the $\mathrm{Ha}, \mathrm{Hb}$ and Hx atoms of the pyrazoline ring, respectively.

\section{Absorption and emission properties}

The electronic properties of compounds $\mathbf{3 c}, \mathbf{3 f}, \mathbf{4 c}$ and $\mathbf{4 f}$ in acetonitrile were studied by absorption and fluorescence spectroscopy because of their outstanding emission properties in solution and solid state. In the absorption spectra of all compounds, a strong band around 229-239 nm associated to $\pi$ - $\pi^{*}$ transition is observed; compounds $3 \mathbf{c}$ and 3f show an additional $\pi-\pi *$ transition around $262-264 \mathrm{~nm}$ as a shoulder; the $n-\pi^{*}$ transitions for $\mathbf{3 c}$ and $\mathbf{3 f}$ are shifted to higher energy values than the same transitions for $\mathbf{4 c}$ and $\mathbf{4 f}$ due to the presence of nitrogen atoms in the pyrazoline ring of the latter (Figure 1). Table 2 summarizes the absorption and emission data.

The emission spectra of compounds $\mathbf{3 c}, \mathbf{3 f}, \mathbf{4 c}$ and $\mathbf{4 f}$ (Figure 1) were measured in acetonitrile as solvent at $\lambda_{\max }$ as excitation wavelength. This value is also near to the excitation wavelength of rhodamine B as standard.

In this way, a broad emission band can be seen at $370-449 \mathrm{~nm}\left(\lambda_{\mathrm{em}}\right)$ for all compounds (Figure 2); additionally, compound $3 \mathbf{c}$ exhibits a second emission band at $483 \mathrm{~nm}$, an indication that the deactivation emission pathways are the same for compounds $\mathbf{3 f}, \mathbf{4} \mathbf{c}$ and $\mathbf{4 f}$. On

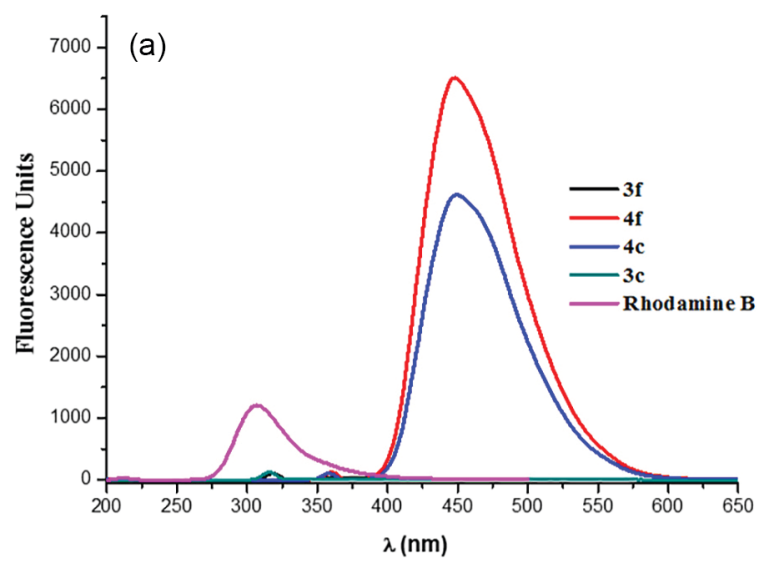

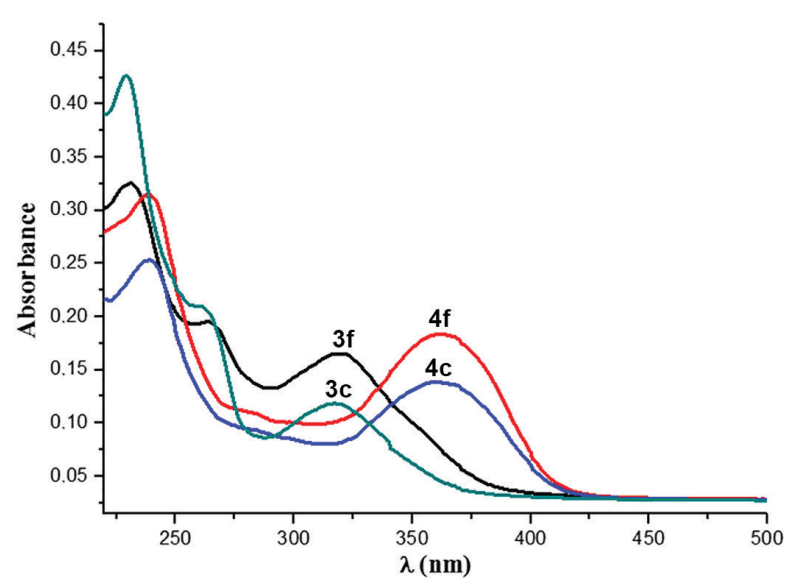

Figure 1. Absorption spectra of compounds $\mathbf{3 c}, \mathbf{3 f}, \mathbf{4 c}$ and $\mathbf{4 f}$ in acetonitrile at room temperature.

the other hand, the shapes between the absorption and fluorescence spectra of compound $\mathbf{3 c}$ are quite different, which indicate different exciton structures between the ground and excited states in such molecule, according to the Kasha model. ${ }^{32,33}$

The fluorescence quantum yields $(\Phi)$ were calculated from equation 1 using rhodamine $\mathrm{B}$ in acetonitrile as the standard.

$\Phi_{\mathrm{F}}=\Phi_{\mathrm{F}}^{\mathrm{std}} \frac{\mathrm{FA}^{\mathrm{std}} \mathrm{In}^{2}}{\mathrm{~F}^{\mathrm{std}} \mathrm{AI}^{\mathrm{std}} \mathrm{n}_{\text {std }}^{2}}$

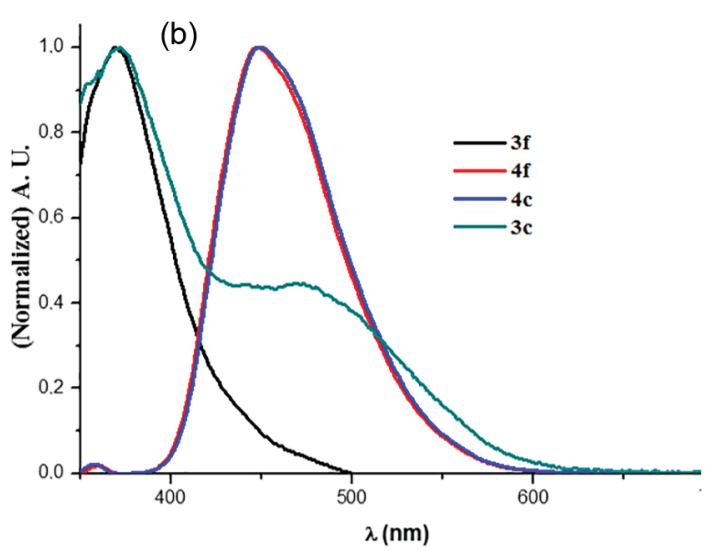

Figure 2. (a) Emission spectra of compounds $\mathbf{3 c}, \mathbf{3 f}, \mathbf{4} \mathbf{c}$ and $\mathbf{4 f}$ in acetonitrile at room temperature; (b) normalized emission spectra of compounds $\mathbf{3 c}, \mathbf{3 f}$, $4 c$ and $4 f$. 
where $\mathrm{F}$ and $\mathrm{F}^{\text {std }}$ are the areas under the fluorescence curves of the compounds and the standard, respectively; A and $\mathrm{A}^{\text {std }}$ are the absorbance peaks of the sample and standard at the excitation wavelengths, respectively; I and Itd are the relative intensities of the exciting lights of the samples and the standard, respectively; and $\mathrm{n}^{2}$ and $\mathrm{n}_{\text {std }}^{2}$ are the refractive indices of the solvents used for the sample and standard, respectively.

According to equation 1, the experimental quantum yields $(\Phi)$ of compounds $\mathbf{4 c}$ and $\mathbf{4 f}$ are higher (0.593-0.740) than those of compounds $3 \mathbf{c}$ and $\mathbf{3 f}\left(1.15 \times 10^{-3}-6.72 \times 10^{-3}\right)$, even higher than rhodamine $\mathrm{B}$, due to the lowest unoccupied molecular orbital (LUMO) stabilization of pyrazoline ring, this fact indicates the ease of the excitonic states deactivation. As shown in Figure 2, the areas under the fluorescence curves of compounds $\mathbf{4 c}$ and $\mathbf{4 f}$ are higher than the rhodamine $\mathrm{B}$. This phenomenon is favored by the reduction of the emission energy gap of the compounds mentioned above, which is due to the introduction of the nitrogen atoms of the heterocyclic ring.

We made theoretical calculations at time-dependent density functional theory (TD-DFT) level, using B3LYP as hybrid functional and 6-31G++ as basis set to determine the minimum energy geometry. In addition, we used the polarization continuum method (PCM) model to simulate the electronic excited state properties in the presence of acetonitrile as solvent, in order to explain the absorption behaviors of the obtained compounds $\mathbf{3 c}, \mathbf{3 f}, \mathbf{4 c}$ and $\mathbf{4 f}$. The theoretical data for electronic excited states are summarized in Table 3. Importantly, the calculated transition energies are close in regard to the experimental transition energies (see Table 3), although it is clear that the theoretical method used in this work underestimates the energy values for both electronic transitions; this trend is usual in DFT calculations.

Table 3. Theoretical data for electronic excited states of compounds $\mathbf{3 c}$, $3 f, 4 c$ and $\mathbf{4 f}$

\begin{tabular}{|c|c|c|c|}
\hline Compound & Excited state & Energy / eV & $\begin{array}{c}\text { Oscillator } \\
\text { strength }\end{array}$ \\
\hline \multirow{3}{*}{$3 c$} & $\mathrm{~S}_{1}(\mathrm{HOMO} \rightarrow \mathrm{LUMO})$ & 3.0054 & 0.6476 \\
\hline & $\mathrm{S}_{2}(\mathrm{HOMO}-1 \rightarrow \mathrm{LUMO})$ & 3.3034 & 0.2796 \\
\hline & $\mathrm{S}_{3}(\mathrm{HOMO}-2 \rightarrow \mathrm{LUMO}+3)$ & 4.4727 & 0.2702 \\
\hline \multirow{3}{*}{ 3f } & $\mathrm{S}_{1}(\mathrm{HOMO} \rightarrow \mathrm{LUMO})$ & 2.9649 & 0.4048 \\
\hline & $\mathrm{S}_{2}(\mathrm{HOMO}-2 \rightarrow \mathrm{LUMO})$ & 3.5798 & 0.6530 \\
\hline & $\mathrm{S}_{3}(\mathrm{HOMO}-3 \rightarrow \mathrm{LUMO})$ & 3.8339 & 0.2857 \\
\hline \multirow{2}{*}{$4 c$} & $\mathrm{~S}_{1}(\mathrm{HOMO} \rightarrow \mathrm{LUMO})$ & 3.1861 & 0.8954 \\
\hline & $\mathrm{S}_{2}(\mathrm{HOMO}-1 \rightarrow \mathrm{LUMO}+1)$ & 4.7825 & 0.7375 \\
\hline \multirow{2}{*}{$4 f$} & $\mathrm{~S}_{1}(\mathrm{HOMO} \rightarrow \mathrm{LUMO})$ & 2.7985 & 0.8972 \\
\hline & $\mathrm{S}_{2}(\mathrm{HOMO}-1 \rightarrow$ LUMO) & 4.7448 & 0.4165 \\
\hline
\end{tabular}

Frontier orbital diagram for photophysic process for $\mathbf{4 f}$ (Figure 3) can be used to explain the experimental features in the absorption and emission spectra measured. According to the observed experimental data and their relationship to those found computationally, the highest energy occupied molecular orbital (HOMO) to LUMO transition generates (PET behavior) a first excited state (S1) with an additional transition between HOMO-1 and LUMO to generate the excited state (S2); the emission process can be ascribed to a LUMO to HOMO (among some of his vibrational states) decay; in this way, the LUMO to HOMO-1 decay is slightly promoted with several non-radiative decay processes.

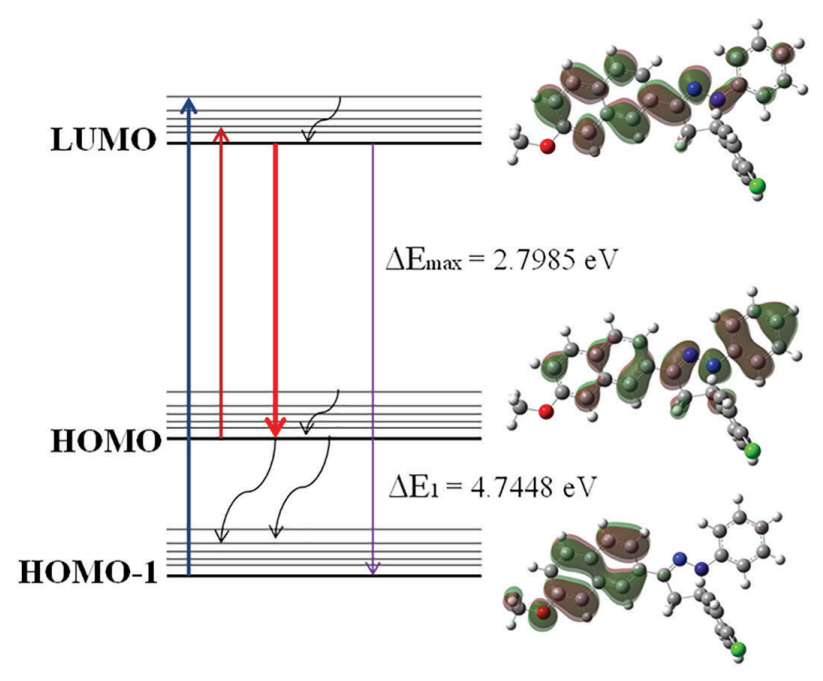

Figure 3. Energy levels diagram for photo-physic process of $\mathbf{4 f}$ (absorption and emission).

\section{Conclusions}

We synthesized seven pyrazoline derivatives, four new and three already reported in the literature, through a simple synthetic sequence with low environmental impact. The characteristic of this work is the variation in the conditions of classical reactions and incorporation of recognized chromophores in the target structure. Compounds $\mathbf{4 c}$ and $\mathbf{4 f}$ may represent a new alternative as materials in luminescence applications due to the interesting $\pi-\pi^{*}$ and $n-\pi^{*}$ bands exhibited in the absorption spectra with remarkable $\varepsilon$ values between $1.39 \times 10^{4}$ and $1.84 \times 10^{4} \mathrm{M}^{-1} \mathrm{~cm}^{-1}$. Furthermore, the fluorescence quantum yields (0.593-0.740) are in the range of the analytical and biological qualitative and quantitative probes.

\section{Experimental}

All materials, reagents and solvents reagent grade are commercial (Merck or Aldrich Chemical Company). Melting points were determined using a Thermo Scientific 
Fluke 51 II, model IA 9100 melting point apparatus and are reported uncorrected. ${ }^{1} \mathrm{H}$ NMR $(400 \mathrm{MHz})$ and ${ }^{13} \mathrm{C} \mathrm{NMR}$ (100 MHz) spectra of compounds (in dimethyl sulfoxide, DMSO- $d_{6}$ ) were recorded at room temperature on a Bruker Ultra Shield 400. Peak multiplicities were designed as: $\mathrm{s}$, singlet; d, doublet; $\mathrm{t}$, triplet; $\mathrm{m}$, multiplet; dd, double doublet. Chemical shifts were reported as $\delta$ (ppm) relative tetramethylsilane (TMS) as internal standard and coupling constants $(J)$ were reported in hertz $(\mathrm{Hz})$. The EI-MS were run on a Shimadzu GC-MS 2010 spectrometer, which was operating at $70 \mathrm{eV}$. The elemental analyses were performed on a LECO CHNS-900 elemental analyzer and the values are within $\pm 0.4 \%$ of theoretical values.

Ultrasonic irradiation was performed by using a Branson ultrasonic cleaner bath, model 1510, 115v, 1.9 L with mechanical timer (60 min with continuous hold) and heater switch, $47 \mathrm{kHz}$. Progress of reaction was monitored by thin-layer chromatography (TLC) on $\mathrm{F}_{254}$ silica-gel pre coated sheets (Merck, Darmstadt, Germany), revealed under UV light ( 254 and $365 \mathrm{~nm}$ ), with ethyl acetate:hexane $(3: 7 \mathrm{v} / \mathrm{v})$ as solvent systems. The resulting solid was filtered and purified by recrystallization from methanol or ethanol/ hexane mixture.

General procedure for synthesis of $(E)$-1-(3-aryl)(2-methoxynaphthalen-6-yl)-prop-2-en-1-one (3a-g)

A mixture of 1-(2-methoxynaphthalen-6-yl)ethanone (1 mmol), $\mathrm{NaOH} 40 \%(1 \mathrm{~mL})$ and methanol $(3 \mathrm{~mL})$, was sonicated for $30 \mathrm{~s}$ in the water bath of an ultrasonic cleaner bath. Then, the respective aromatic aldehyde was added $(1.5 \mathrm{mmol})$ and the sonication continued. The precipitate was filtered and recrystallized from methanol.

\section{(E)-1-(2-Methoxynaphthalen-6-yl)-3-p-tolylprop-2-en-1-one} (3a)

Yield 80\%; mp 166-169 ${ }^{\circ} \mathrm{C}$; ${ }^{1} \mathrm{H}$ NMR (400 MHz, DMSO- $\left.d_{6}\right) \delta 8.87(\mathrm{~s}, 1 \mathrm{H}), 8.11(\mathrm{~d}, 1 \mathrm{H}), 8.10(\mathrm{~s}, 1 \mathrm{H}), 8.06$ $(\mathrm{d}, 1 \mathrm{H}), 7.94(\mathrm{~d}, 1 \mathrm{H}), 7.82(\mathrm{~d}, 2 \mathrm{H}, J$ 8.0, Ho), $7.76(\mathrm{~d}, 1 \mathrm{H}$,

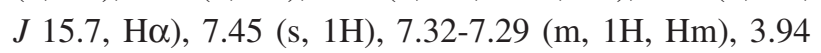
$\left(\mathrm{s}, 3 \mathrm{H}, \mathrm{OCH}_{3}\right), 2.38\left(\mathrm{~s}, 3 \mathrm{H}, \mathrm{CH}_{3}\right) ;{ }^{13} \mathrm{C}$ NMR $(100 \mathrm{MHz}$, DMSO- $\left.d_{6}\right) \delta 188.4(\mathrm{C}=\mathrm{O}), 159.4,143.5(\mathrm{C} \beta), 140.6(\mathrm{Cp})$, $136.9,132.9,132.1,131.2,130.3,129.5(\mathrm{Cm}), 128.9(\mathrm{Co})$, 127.6, 127.2, 124.8, $121.0(\mathrm{C} \alpha), 119.5,106.1,55.4\left(\mathrm{OCH}_{3}\right)$, $21.1\left(\mathrm{CH}_{3}\right)$; MS (ESI, positive scan $\left.70 \mathrm{eV}\right) \mathrm{m} / \mathrm{z}, 302\left[\mathrm{M}^{+}\right]$; anal. calcd. for $\mathrm{C}_{21} \mathrm{H}_{18} \mathrm{O}_{2}$ : C 83.42, H 6.00, found: C 83.41, H 6.03 .

(E)-1-(2-Methoxynaphthalen-6-yl)-3-(4-methoxyphenyl) prop-2-en-1-one (3b)

Yield 81\%; mp 131-134 ${ }^{\circ} \mathrm{C}$; ${ }^{1} \mathrm{H}$ NMR $(400 \mathrm{MHz}$,
DMSO- $\left.d_{6}\right) \delta 8.83(\mathrm{~s}, 1 \mathrm{H}), 8.11(\mathrm{~d}, 1 \mathrm{H}), 8.07(\mathrm{~d}, 1 \mathrm{H})$, 7.97 (d, 1H, J 15.7, H $\beta$ ), 7.94 (d, 1H), 7.89 (d, 2H, J 8.8,

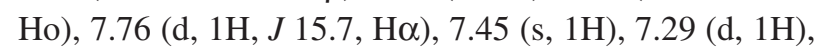
7.05 (d, 2H, J 8.8, Hm), $3.92\left(\mathrm{~s}, 1 \mathrm{H}, \mathrm{OCH}_{3}\right), 3.83(\mathrm{~s}, 1 \mathrm{H}$, $\left.\mathrm{OCH}_{3}\right) ;{ }^{13} \mathrm{C}$ NMR (100 MHz, DMSO- $\left.d_{6}\right) \delta 188.3(\mathrm{C}=\mathrm{O})$, 161.3 (Cp), 159.4, 143.4 (C $\beta), 136.8,133.1,131.2,130.7$ (Co), 130.1 (Ci), 127.6, 127.5, 127.2, 124.8, $119.6(\mathrm{C} \alpha)$, 119.5, $114.4(\mathrm{Cm}), 106.1,55.4\left(\mathrm{OCH}_{3}\right), 55.3\left(\mathrm{OCH}_{3}\right) ; \mathrm{MS}$ (ESI, positive scan $70 \mathrm{eV}$ ) $\mathrm{m} / z, 318\left[\mathrm{M}^{+}\right]$; anal. calcd. for $\mathrm{C}_{21} \mathrm{H}_{18} \mathrm{O}_{3}: \mathrm{C}$ 79.22, H 5.77, found: C 79.23, H 5.73.

(E)-1-(2-Methoxynaphthalen-6-yl)-3-(3,4,5-trimethoxyphenyl)prop-2-en-1-one (3c)

Yield 78\%; mp 126-129 ${ }^{\circ} \mathrm{C} ;{ }^{1} \mathrm{H}$ NMR (400 MHz, DMSO- $\left.d_{6}\right) \delta 8.80(\mathrm{~s}, 1 \mathrm{H}), 8.60(\mathrm{~s}, 1 \mathrm{H}), 8.06(\mathrm{~d}, 1 \mathrm{H}), 8.01$ $(\mathrm{d}, 1 \mathrm{H}, J 15.6, \mathrm{H} \beta), 7.96(\mathrm{~d}, 1 \mathrm{H}), 7.92(\mathrm{~d}, 1 \mathrm{H}), 7.85(\mathrm{~d}, 1 \mathrm{H})$, 7.72 (d, 1H, J 15.6, H $\alpha$ ), 6.65 (s, 2H, H aryl), 3.92-3.88 $\left(\mathrm{m}, 12 \mathrm{H}, \mathrm{OCH}_{3}\right) ;{ }^{13} \mathrm{C} \mathrm{NMR}\left(100 \mathrm{MHz}\right.$, DMSO- $\left.d_{6}\right) \delta 198.8$ $(\mathrm{C}=\mathrm{O}), 188.8,159.6,153.4,152.8,144.3,137.1,136.2$, 131.4, 130.1, 127.7, 127.3, 125.2, 124.5, 121.6, 119.8, 106.8, 106.3, 105.3, $56.5\left(\mathrm{OCH}_{3}\right), 56.1\left(\mathrm{OCH}_{3}\right), 55.7\left(\mathrm{OCH}_{3}\right) ; \mathrm{MS}$ (ESI, positive scan $70 \mathrm{eV}$ ) $\mathrm{m} / \mathrm{z}, 378\left[\mathrm{M}^{+}\right]$; anal. calcd. for $\mathrm{C}_{23} \mathrm{H}_{22} \mathrm{O}_{5}$ : C 73.00, H 5.86, found: C 73.03, H 5.89.

(E)-3-(Benzo[d][1,3]dioxol-5-yl)-1-(2-methoxynaphthalen6-yl)prop-2-en-1-one (3d)

Yield 76\%; mp 170-173 ${ }^{\circ} \mathrm{C}$; ${ }^{1} \mathrm{H}$ MNR (400 MHz, DMSO- $\left.d_{6}\right) \delta 8.85(\mathrm{~s}, 1 \mathrm{H}), 8.10(\mathrm{~d}, 1 \mathrm{H}), 8.04(\mathrm{~d}, 1 \mathrm{H}), 7.96$ $(\mathrm{d}, 1 \mathrm{H}, J 15.2, \mathrm{H} \beta), 7.91(\mathrm{~d}, 1 \mathrm{H}), 7.70(\mathrm{~d}, 1 \mathrm{H}, J 15.2, \mathrm{H} \alpha)$, 7.69 (s, 1H, naphtyl), $7.42(\mathrm{~s}, 1 \mathrm{H}$, aryl), $7.34(\mathrm{~d}, 1 \mathrm{H}), 7.27$ $(\mathrm{d}, 1 \mathrm{H}), 7.00(\mathrm{~d}, 1 \mathrm{H}), 6.12\left(\mathrm{~s}, 2 \mathrm{H}, \mathrm{CH}_{2}\right), 3.92\left(\mathrm{~s}, 3 \mathrm{H}, \mathrm{CH}_{3}\right)$; ${ }^{13} \mathrm{C}$ NMR (100 MHz, DMSO- $\left.d_{6}\right) \delta 188.3(\mathrm{C}=\mathrm{O}), 159.4$, 149.5, 148.1, $143.5(\mathrm{C} \beta), 136.9,133.0,131.2,130.2,129.4$, 127.6, 127.2, $125.8(\mathrm{C} \alpha), 124.8,120.0,119.5,108.6,106.9$, 106.1, $101.7\left(\mathrm{CH}_{2}\right), 55.4\left(\mathrm{OCH}_{3}\right)$; MS (ESI, positive scan $70 \mathrm{eV}$ ) $\mathrm{m} / z, 332\left[\mathrm{M}^{+}\right]$; anal. calcd. for $\mathrm{C}_{21} \mathrm{H}_{16} \mathrm{O}_{4}: \mathrm{C} 75.89$, H 4.85, found: C 75.87, H 4.82 .

(E)-1,3-bis(2-Methoxynaphthalen-6-yl)prop-2-en-1-one (3e) Yield 77\%; mp 210-213 ${ }^{\circ} \mathrm{C} ;{ }^{1} \mathrm{H}$ NMR (400 MHz, DMSO- $\left.d_{6}\right) \delta 8.90(\mathrm{~s}, 1 \mathrm{H}), 8.28(\mathrm{~s}, 1 \mathrm{H}), 8.20-8.08(\mathrm{~m}, 4 \mathrm{H})$, 7.97-7.90 (m, 4H), $7.40(\mathrm{~d}, 2 \mathrm{H}), 7.29(\mathrm{~d}, 1 \mathrm{H}), 7.22(\mathrm{~d}, 1 \mathrm{H})$, 3.93-39.1 (s, 6H, $\left.\mathrm{OCH}_{3}\right) ;{ }^{13} \mathrm{C} \mathrm{NMR}\left(100 \mathrm{MHz}\right.$, DMSO- $\left.d_{6}\right) \delta$ $188.5(\mathrm{C}=\mathrm{O}), 158.7,143.9,137.0,136.1,133.0,131.4,130.7$, 130.3, 128.5, 127.5, 125.2, 121.4, 119.8, 119.4, 106.4, 63.2, 55.5; MS (ESI, positive scan $70 \mathrm{eV}$ ) $\mathrm{m} / \mathrm{z}, 368\left[\mathrm{M}^{+}\right]$; anal. calcd. for $\mathrm{C}_{25} \mathrm{H}_{20} \mathrm{O}_{3}: \mathrm{C} 81.50, \mathrm{H}$ 5.47, found: C 81.54, H 5.46.

(E)-3-(4-Chlorophenyl)-1-(2-methoxynaphthalen-6-yl)prop2-en-1-one (3f)

Yield 80\%; mp 166-169 ${ }^{\circ} \mathrm{C}$; ${ }^{1} \mathrm{H}$ NMR (400 MHz, 
DMSO- $\left.d_{6}\right) \delta 8.86(\mathrm{~s}, 1 \mathrm{H}), 8.10(\mathrm{~d}, 1 \mathrm{H}), 8.05(\mathrm{~d}, 1 \mathrm{H})$, 7.97-7.93 (t, 3H), $7.76(\mathrm{~s}, 1 \mathrm{H}), 7.53$ (d, 2H, J 8.6, Ho), 7.43-7.41 (m, 2H), $7.28(\mathrm{~d}, 1 \mathrm{H}), 3.92\left(\mathrm{~s}, 3 \mathrm{H}, \mathrm{OCH}_{3}\right)$; ${ }^{13} \mathrm{C}$ NMR (100 MHz, DMSO- $\left.d_{6}\right) \delta 188.3(\mathrm{C}=\mathrm{O}), 159.5$, 141.8, 137.0 (Cp), 135.0, 133.8, 132.7, 131.2, 130.5 (Co), $128.9(\mathrm{Cm}), 127.5,127.2,124.7,119.5,106.1,55.4$ $\left(\mathrm{OCH}_{3}\right)$; MS (ESI, positive scan $\left.70 \mathrm{eV}\right) \mathrm{m} / z, 322\left[\mathrm{M}^{+}\right]$; anal. calcd. for $\mathrm{C}_{20} \mathrm{H}_{15} \mathrm{ClO}_{2}$ : C 74.41, H 4.68, found: C 74.42, H 4.66 .

(E)-1-(2-Methoxynaphthalen-6-yl)-3-(4-nitrophenyl)prop2-en-1-one (3g)

Yield 65\%; mp 198-201 ${ }^{\circ} \mathrm{C}$; ${ }^{1} \mathrm{H}$ NMR $(400 \mathrm{MHz}$, DMSO- $\left.d_{6}\right) \delta 8.88(\mathrm{~s}, 1 \mathrm{H}), 8.30-8.26(\mathrm{~m}, 3 \mathrm{H}), 8.17(\mathrm{~d}, 2 \mathrm{H}$, $J$ 8.4, Ho), $8.10(\mathrm{~d}, 1 \mathrm{H}), 8.05(\mathrm{~d}, 1 \mathrm{H}), 7.93(\mathrm{~d}, 1 \mathrm{H}), 7.82$

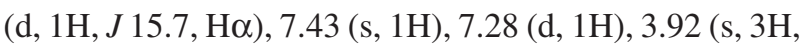
$\left.\mathrm{OCH}_{3}\right) ;{ }^{13} \mathrm{C}$ NMR $\left(100 \mathrm{MHz}\right.$, DMSO- $\left.d_{6}\right) \delta 188.5(\mathrm{C}=\mathrm{O})$, 159.9, $148.3(\mathrm{Cp}), 141.6(\mathrm{C} \beta), 140.8,137.4,131.6,131.1$, $130.0(\mathrm{Co}), 127.6,126.4,124.9(\mathrm{C} \alpha), 124.2(\mathrm{Cm}), 119.8$, 106.5, $55.7\left(\mathrm{OCH}_{3}\right)$; MS (ESI, positive scan $\left.70 \mathrm{eV}\right) \mathrm{m} / \mathrm{z}$, $333\left[\mathrm{M}^{+}\right]$; anal. calcd. for $\mathrm{C}_{20} \mathrm{H}_{15} \mathrm{NO}_{4}$ : C 72.06, $\mathrm{H} 4.54$, $\mathrm{N}$ 4.20, found: C 72.02, H 4.56, N 4.16.

General procedure for synthesis of 5-aryl-3-(2-methoxynaphthalen-6-yl)-1-phenylpyrazoline (4a-g)

A mixture of (E)-1-(3-aryl)-(2-methoxynaphthalen6-yl)-prop-2-en-1-ones (3a-g, $1 \mathrm{mmol})$, phenylhydrazine (3 mmol) in $\mathrm{CH}_{3} \mathrm{COOH} / \mathrm{H}_{2} \mathrm{O} 7: 3(3 \mathrm{~mL})$ was refluxed for 3-4.5 h. After completion, the reaction mixture was cooled to room temperature and the precipitate was filtered, dried and recrystallized from ethanol/hexane mixture.

4,5-Dihydro-3-(2-methoxynaphthalen-6-yl)-1-phenyl5-p-tolyl-1 $\mathrm{H}$-pyrazoline (4a)

Yield 75\%; mp 228-231 ${ }^{\circ} \mathrm{C}$; ${ }^{1} \mathrm{H}$ NMR (400 MHz, DMSO- $\left.d_{6}\right) \delta 8.04(\mathrm{~d}, 1 \mathrm{H}), 7.97(\mathrm{~s}, 1 \mathrm{H}), 7.82(\mathrm{dd}, 2 \mathrm{H}), 7.35$ (s, 1H), 7.21-7.13 (m, 7H), 7.02 (d, 2H, J 7.7, Hm-aryl), 6.71 (t, 1H, J 7.2, Hp), 5.45 (dd, 1H, CH-pyrazoline), 3.95 (dd, 1H, CH-pyrazoline), 3.89 (s, 3H, $\mathrm{OCH}_{3}$ ), 3.15 (dd, $1 \mathrm{H}, \mathrm{CH}$-pyrazoline), 2.25 (s, $3 \mathrm{H}, \mathrm{CH}_{3}$-aryl); ${ }^{13} \mathrm{C} \mathrm{NMR}$ $\left(100 \mathrm{MHz}\right.$, DMSO- $\left.d_{6}\right) \delta 129.3,128.6,125.6,123.3,118.7$, 118.2, 112.7, 62.8 (C-pyrazoline), 58.1, 55.0 $\left(\mathrm{OCH}_{3}\right), 42.9$ $\left(\mathrm{CH}_{2}\right), 20.3\left(\mathrm{CH}_{3}\right.$-aryl); MS (ESI, positive scan $\left.70 \mathrm{eV}\right) \mathrm{m} / \mathrm{z}$, $392\left[\mathrm{M}^{+}\right]$; anal. calcd. for $\mathrm{C}_{27} \mathrm{H}_{24} \mathrm{~N}_{2} \mathrm{O}$ : C 82.63, H 6.16, N 7.13, found: C 82.60, H 6.13, N 7.09.

4,5-Dihydro-3-(2-methoxynaphthalen-6-yl)-5-(4-methoxyphenyl)-1-phenyl-1 $H$-pyrazoline (4b)

Yield 70\%; mp 214-217 ${ }^{\circ} \mathrm{C}$; ${ }^{1} \mathrm{H}$ NMR $(400 \mathrm{MHz}$, DMSO- $\left.d_{6}\right) \delta 8.04(\mathrm{~d}, 1 \mathrm{H}), 7.95(\mathrm{~s}, 1 \mathrm{H}), 7.82(\mathrm{~d}, 2 \mathrm{H}), 7.34$ (s, 1H), 7.21 (d, 2H, J 8.3), 7.19-7.14 (m, 3H), 7.03 (d, $2 \mathrm{H}, J$ 8.3), 6.88 (d, 2H), 6.69 (t, Hp-phenyl), 5.42 (dd, 1H, CH-pyrazoline), 3.91 (dd, 1H, CH-pyrazoline), 3.88 (s, 3H, $\left.\mathrm{OCH}_{3}\right), 3.70$ (s, 3H, $\left.\mathrm{OCH}_{3}\right), 3.14$ (dd, $1 \mathrm{H}, \mathrm{CH}$-pyrazoline); ${ }^{13} \mathrm{C}$ NMR (100 MHz, DMSO- $\left.d_{6}\right) \delta 158.5,157.8,147.5$ (C-pyrazoline), 144.3, 134.5, 134.4, 129.7, 128.8, 127.8, 127.1, 127.0, 125.3, 123.6, 118.9, 118.4, 114.3, 113.0, 106.3, 62.6 (CH-pyrazoline), $55.5\left(\mathrm{OCH}_{3}\right), 55.0\left(\mathrm{OCH}_{3}\right)$, $43.0\left(\mathrm{CH}_{2}\right)$; MS (ESI, positive scan $\left.70 \mathrm{eV}\right) \mathrm{m} / \mathrm{z}, 408\left[\mathrm{M}^{+}\right]$; anal. calcd. for $\mathrm{C}_{27} \mathrm{H}_{24} \mathrm{~N}_{2} \mathrm{O}_{2}: \mathrm{C} 79.38, \mathrm{H} 5.92, \mathrm{~N} 6.85$, found: C 79.39, H 5.89, N 6.83 .

4,5-Dihydro-3-(2-methoxynaphthalen-6-yl)-5-(3,4,5-trimethoxyphenyl)-1-phenyl-1 $\mathrm{H}$-pyrazoline (4c)

Yield 70\%; mp 186-189 ${ }^{\circ} \mathrm{C}$; ${ }^{1} \mathrm{H}$ NMR (400 MHz, DMSO- $\left.d_{6}\right) \delta 8.05(\mathrm{~d}, 1 \mathrm{H}), 7.98(\mathrm{~s}, 1 \mathrm{H}), 7.83(\mathrm{~d}, 1 \mathrm{H})$, $7.35(\mathrm{~s}, 1 \mathrm{H}), 7.22-7.18(\mathrm{~m}, 4 \mathrm{H}), 7.05(\mathrm{t}, 2 \mathrm{H}), 6.74(\mathrm{t}, 1 \mathrm{H})$, $6.64(\mathrm{~s}, 2 \mathrm{H}), 5.35$ (dd, 1H, CH-pyrazoline), 3.97 (dd, $1 \mathrm{H}, \mathrm{CH}$-pyrazoline), $3.89\left(\mathrm{~s}, 3 \mathrm{H}, \mathrm{OCH}_{3}\right), 3.70(\mathrm{~s}, 6 \mathrm{H}$, $\left.\mathrm{OCH}_{3}\right), 3.63$ (s, 3H, $\mathrm{OCH}_{3}$ ), 3.21 (dd, 1H, CH-pyrazoline); ${ }^{13} \mathrm{C}$ NMR (100 MHz, DMSO- $\left.d_{6}\right) \delta 157.8,153.3,147.8$, $144.8,138.5,136.5,134.4,129.7,128.9,128.2,127.6$, 127.0, 125.4, 123.7, 118.9, 118.7, 113.1, 106.3, 102.9, 63.8 (CH-pyrazoline), $59.9\left(\mathrm{OCH}_{3}\right), 55.8\left(\mathrm{OCH}_{3}\right), 55.2\left(\mathrm{OCH}_{3}\right)$, $43.2\left(\mathrm{CH}_{2}\right)$; MS (ESI, positive scan $\left.70 \mathrm{eV}\right) \mathrm{m} / \mathrm{z}, 468\left[\mathrm{M}^{+}\right]$; anal. calcd. for $\mathrm{C}_{29} \mathrm{H}_{28} \mathrm{~N}_{2} \mathrm{O}_{4}: \mathrm{C} 74.33, \mathrm{H} 6.02, \mathrm{~N} 5.97$, found: C 74.34, H 6.04, N 5.99.

5-(Benzo[d][1,3]dioxol-5-yl)-4,5-dihydro-3-(2-methoxynaphthalen-6-yl)-1-phenyl-1H-pyrazoline (4d)

Yield 70\%; mp 238-241 ${ }^{\circ} \mathrm{C}$; ${ }^{1} \mathrm{H}$ NMR (400 MHz, DMSO- $\left.d_{6}\right) \delta 8.06(\mathrm{~d}, 1 \mathrm{H}), 7.99(\mathrm{~s}, 1 \mathrm{H}), 7.85(\mathrm{~d}, 2 \mathrm{H}, J 8.8)$, 7.37 (s, 1H), 7.20 (m, 3H), 7.09 (t, 2H, J 8.7, Hm-phenyl), 6.90-6.73 (m, 3H), $6.66(\mathrm{~s}, 1 \mathrm{H}), 5.99\left(\mathrm{~s}, 2 \mathrm{H}, \mathrm{OCH}_{2} \mathrm{O}\right), 5.44$ (dd, 1H, CH-pyrazoline), 3.94 (dd, 1H, CH-pyrazoline), $3.91\left(\mathrm{~s}, 3 \mathrm{H}, \mathrm{OCH}_{3}\right), 3.19$ (dd, $1 \mathrm{H}, \mathrm{CH}-$ pyrazoline); ${ }^{13} \mathrm{C}$ NMR (100 MHz, DMSO- $\left.d_{6}\right) \delta 158.4,153.8,148.2$, 146.9, 145.3, 144.7, 137.0, 134.9, 130.2, 129.4, 128.8, 127.5, 119.5, 113.5, 109.1, 106.8, 103.4, $63.4\left(\mathrm{OCH}_{3}\right)$, 60.4 (CH-pyrazoline), 55.8, $43.5\left(\mathrm{CH}_{2}\right)$; MS (ESI, positive scan $70 \mathrm{eV}$ ) $\mathrm{m} / z, 422\left[\mathrm{M}^{+}\right]$; anal. calcd. for $\mathrm{C}_{27} \mathrm{H}_{22} \mathrm{~N}_{2} \mathrm{O}_{3}$ : C 76.73, H 5.28, N 6.68, found: C 76.76, H 5.25, N 6.63 .

4,5-Dihydro-3,5-bis(2-methoxynaphthalen-6-yl)-1-phenyl$1 \mathrm{H}$-pyrazoline $(\mathbf{4 e})$

Yield 70\%; mp 245-248 ${ }^{\circ} \mathrm{C}$; ${ }^{1} \mathrm{H}$ NMR (400 MHz, DMSO- $\left.d_{6}\right) \delta 8.08(\mathrm{~d}, 1 \mathrm{H}), 8.04(\mathrm{~d}, 1 \mathrm{H}), 7.97(\mathrm{~s}, 2 \mathrm{H}), 7.87-$ $7.78(\mathrm{~m}, 6 \mathrm{H}), 7.20-7.08(\mathrm{~m}, 4 \mathrm{H}), 7.02(\mathrm{~d}, 2 \mathrm{H}), 6.72(\mathrm{t}, 1 \mathrm{H})$, $5.53\left(\mathrm{dd}, 1 \mathrm{H}, \mathrm{CH}-\right.$ pyrazoline), $3.96\left(\mathrm{dd}, 1 \mathrm{H}, \mathrm{CH}_{2}\right), 3.89$ (s, 6H, $\left.\mathrm{OCH}_{3}\right), 3.19$ (dd, 1H, $\left.\mathrm{CH}_{2}\right) ;{ }^{13} \mathrm{C}$ NMR (100 MHz, 
DMSO- $\left.d_{6}\right) \delta 157.8,147.6(\mathrm{Ci}), 141.5,141.4,134.4,131.9$, $129.7,129.0,128.9,128.2,127.8,127.5,127.0,125.4$, 123.6, 119.0, 118.7, 112.9, 106.3, 62.3 (C-pyrazoline), $55.2\left(\mathrm{OCH}_{3}\right), 42.7\left(\mathrm{CH}_{2}\right) ; \mathrm{MS}$ (ESI, positive scan $\left.70 \mathrm{eV}\right)$ $\mathrm{m} / \mathrm{z}, 458\left[\mathrm{M}^{+}\right]$; anal. calcd. for $\mathrm{C}_{31} \mathrm{H}_{26} \mathrm{~N}_{2} \mathrm{O}_{2}$ : C 81.16, H 5.71, N 6.11, found: C 81.20, H 5.72, N 6.09.

5-(4-Chlorophenyl)-4,5-dihydro-3-(2-methoxynaphthalen6-yl)-1-phenyl-1 $\mathrm{H}$-pyrazoline (4f)

Yield 73\%; mp 219-222 ${ }^{\circ} \mathrm{C}$; ${ }^{1} \mathrm{H}$ NMR (400 MHz, DMSO- $\left.d_{6}\right) \delta 8.08(\mathrm{~d}, 1 \mathrm{H}), 7.99(\mathrm{~s}, 1 \mathrm{H}), 7.87(\mathrm{~d}, 1 \mathrm{H}), 7.84$ (d, 1H), 7.41 (d, 2H, J 8.7, Hm-aryl), 7.37-7.34 (m, 1H, Ho-aryl), 7.22-7.19 (m, 1H, Hm-phenyl), 7.04 (d, 2H, J 8.1, Ho-phenyl), 6.75 (t, 1H, J 7.3, Hp-phenyl), 5.58 (dd, 1H, CH-pyrazoline), 4.01 (dd, 1H, CH-pyrazoline), 3.91 (s, 3H, $\mathrm{OCH}_{3}$ ), 3.25 (dd, 1H, CH-pyrazoline); ${ }^{13} \mathrm{C} \mathrm{NMR} \mathrm{(100} \mathrm{MHz,}$ DMSO- $\left.d_{6}\right) \delta 158.0,147.7,144.2,141.6,134.5,132.0$, $129.8,129.1$, 129.0, 128.3, 128.0, 127.6, 127.2, 125.5, $123.7,119.1,118.8,113.0,106.4,62.5$ (CH-pyrazoline), $55.4\left(\mathrm{OCH}_{3}\right), 42.9\left(\mathrm{CH}_{2}\right)$; MS (ESI, positive scan $\left.70 \mathrm{eV}\right)$ $m / z, 412\left[\mathrm{M}^{+}\right]$; anal. calcd. for $\mathrm{C}_{26} \mathrm{H}_{21} \mathrm{ClN}_{2} \mathrm{O}$ : C 75.65, H 5.12, N 6.74, found: C 75.63, H 5.13, N 6.78.

4,5-Dihydro-3-(2-methoxynaphthalen-6-yl)-5-(4-nitrophenyl)-1-phenyl-1 $\mathrm{H}$-pyrazoline (4g)

Yield 75\%; mp 222-225 ${ }^{\circ} \mathrm{C}$; ${ }^{1} \mathrm{H}$ NMR (400 MHz, DMSO- $\left.d_{6}\right) \delta 8.23(\mathrm{~d}, 2 \mathrm{H}, J$ 8.5, Hm-aryl), 8.07 (d, 1H), 8.00 (s, 1H), 7.86 (t, 2H, J 8.2, Hm-phenyl), 7.60 (d, 2H, $J$ 8.5, Ho-aryl), 7.37 (s, 1H), $7.21(\mathrm{~m}, 3 \mathrm{H}), 7.04(\mathrm{~d}, 2 \mathrm{H}$, $J$ 8.3, Ho-phenyl), 6.77 (t, Hp-phenyl), 5.71 (dd, 1H, CH-pyrazoline), 4.04 (dd, 1H, CH-pyrazoline), 3.90 (s, $\mathrm{OCH}_{3}$ ), 3.26 (dd, 1H, CH-pyrazoline); ${ }^{13} \mathrm{C} \mathrm{NMR}(100 \mathrm{MHz}$, DMSO- $\left.d_{6}\right) \delta 158.4,150.6,148.3,147.4,144.5,135.0$, 130.2 , 129.5, 127.8, 127.6, 126.1, 124.8, 124.1, 119.5, 119.4, 113.4, 106.8, 62.9 (C-pyrazoline), $55.7\left(\mathrm{OCH}_{3}\right)$, $43.1\left(\mathrm{CH}_{2}\right)$; MS (ESI, positive scan $\left.70 \mathrm{eV}\right) \mathrm{m} / z, 423\left[\mathrm{M}^{+}\right]$; anal. calcd. for $\mathrm{C}_{26} \mathrm{H}_{21} \mathrm{~N}_{3} \mathrm{O}_{3}: \mathrm{C} 73.79, \mathrm{H} 4.97$, N 9.90, found: C 73.75, H 5.00, N 9.92.

UV-Vis absorption and fluorescence measurements

UV-Vis absorption spectra were measured on a Jasco V-730 spectrophotometer, using fused quartz glass cuvettes with $10.0 \mathrm{~mm}$ optical path and $1 \times 10^{-5} \mathrm{M}$ solutions of $\mathbf{3 c}, \mathbf{3 f}, \mathbf{4 c}$ and $\mathbf{4 f}$ in acetonitrile as solvent. Fluorescence measurements were performed on a Jasco spectrofluorometer (FP-8500) using fulling transparent fused quartz glass cuvettes with $10.0 \mathrm{~mm}$ optical path, $1 \times 10^{-6} \mathbf{M}$ solutions of $\mathbf{3 c}, \mathbf{3 f}, \mathbf{4 c}$ and $\mathbf{4 f}$ in acetonitrile as solvent and rhodamine $\mathrm{B}$ as fluorescence standard.

\section{Computational detail}

The theoretical calculations were performed using the Gaussian 09 package ${ }^{34}$ with a DFT method, a hybrid functional type B3LYP and 6-31G++ basis set. The $\mathbf{3 c}, \mathbf{3 f}, \mathbf{4 c}$ and $\mathbf{4 f}$ geometry optimization was carried out in ground state and the excited states were performed by a SCF-TD with polarization continuum method (PCM) in acetonitrile as solvent.

\section{Supplementary Information}

Supplementary information (MS, ${ }^{1} \mathrm{H}$ and ${ }^{13} \mathrm{C}$ NMR spectra for $\mathbf{3}$ and $\mathbf{4}$ ) is available free of charge at http://jbcs.sbq.org.br as PDF file.

\section{Acknowledgments}

J. T., A. P. and E. P. P. thank the Universidad del Atlántico for its $7^{\text {th }}$ internal call: Fortalecimiento a Grupos de Investigación de la Universidad del Atlántico-Cb36Fgi2016. A. O. and J. Q. thank Universidad del Valle and the Science, Technology and Innovation Fund-General Royalties System (FCTeI-SGR) under contract BPIN 2013000100007 for financial support.

\section{References}

1. Sharma, S.; Kaur, S.; Bansal, T.; Gaba, J.; Chem. Sci. Trans. 2014, 3, 861 .

2. Akranth, M.; Ali, R.; Alam, T.; Rikta, S.; Omprakash, T.; Mymoona, A.; Shaquiquzzaman, Md.; Mumtaz, A. M.; MiniRev. Med. Chem. 2013, 13, 921.

3. Rahman, A.; Siddiqui, A. A.; Int. J. Pharm. Sci. Drug Res. 2010 , $2,165$.

4. Secci, D.; Carradori, S.; Bolasco, A.; Bizzarri, B.; D’Ascenzio, M.; Maccioni, E.; Curr. Top. Med. Chem. 2012, 12, 2240.

5. Ramkumar, V.; Kannan, P.; Opt. Mater. 2015, 46, 605.

6. Mysliwiec, J.; Szukalski, A.; Sznitko, L.; Miniewicz, A.; Haupa, K.; Zygadlo, K.; Matczyszyn, K.; Olesiak-Banska, J.; Samoc, M.; Dyes Pigm. 2014, 102, 63.

7. Szukalski, A.; Sznitko, L.; Cyprych, K.; Miniewicz, A.; Mysliwiec, J.; J. Phys. Chem. C 2014, 118, 8102.

8. Gong, Z. L.; Zheng, L. W.; Zhao, B. X.; Yang, D. Z.; Lv, H. S.; Liu, W. Y.; Lian, S.; J. Photochem. Photobiol., A 2010, 209, 49.

9. Behbehani, H.; Ibrahima, H. M.; Dawooda, K. M.; RSC Adv. 2015, 5, 25642.

10. Shanmugavelan, P.; Sathishkumar, M.; Nagarajan, S.; Ponnuswamy, A.; Chin. Chem. Lett. 2014, 25, 146.

11. Hawaiz, F. E.; Hussein, A. J.; Samad, M. K.; Eur. J. Chem. 2014, 5, 233. 
12. Thirunarayanan, G.; Mayavel, P.; Thirumurthy, K.; Kumar, S. D.; Sasikala, R.; Nisha, P.; Nithyaranjani, A.; Eur. Chem. Bull. 2013, 2, 598 .

13. Zangade, S. B.; Mokle, S. S.; Shinde, A. T.; Vibhute, Y. B.; Green Chem. Lett. Rev. 2013, 6, 123.

14. Sharifzadeh, B.; Mahmoodi, N. O.; Mamaghani, M.; Tabatabaeian, K.; Chirani, A. S.; Nikokar, I.; Bioorg. Med. Chem. Lett. 2013, 23, 548.

15. Kucukoglu, K.; Oral, F.; Aydin, T.; Yamali, C.; Algul, O.; Sakagami, H.; Gulcin, I.; Supuran, C. T.; Gul, H. I.; J. Enzyme Inhib. Med. Chem. 2016, 31, 20.

16. Indorkar, D.; Chourasia, O. P.; Limaye, S. N.; Int. J. Curr. Microbiol. Appl. Sci. 2015, 4, 670.

17. Zhang, F. G.; Wei, Y.; Yi, Y. P.; Nie, J.; Ma, J. A.; Org. Lett. 2014, 16, 3122.

18. Zhua, S. L.; Wua, Y.; Liu, C. J.; Wei, C. Y.; Tao, J. C.; Liu, H. M.; Eur. J. Med. Chem. 2013, 65, 70.

19. Dong, B.; Wang, M.; Xu, C.; Luminescence 2013, 28, 628.

20. Hasan, A.; Abbas, A.; Akhtar, M. N.; Molecules 2011, 16, 7789.

21. Wang, H. Y.; Zhang, X. X.; Shi, J. J.; Chen, G.; Xu, X. P.; Ji, S. J.; Spectrochim. Acta, Part A 2012, 93, 343.

22. Pramanik, S.; Banerjee, P.; Sarkar, A.; Mukherjee, A.; Mahalanabis, K. K.; Bhattacharya, S. C.; Spectrochim. Acta, Part A 2008, 71, 1327.

23. Pacheco, D. J.; Prent, L.; Trilleras, J.; Quiroga, J.; Ultrason. Sonochem. 2013, 20, 1033.

24. Trilleras, J.; Polo, E.; Quiroga, J.; Cobo, J.; Nogueras, M.; Appl. Sci. 2013, 3, 457.

25. de la Torre, P.; García-Beltrán, O.; Tiznado, W.; Mena, N.; Astudillo Saavedra, L.; Gutiérrez Cabrera, M.; Trilleras, J.; Pavez, J.; Aliaga, M. E.; Sens. Actuators, B 2014, 193, 391.

26. Bukhari Syed, N. A.; Malina, J.; Ibrahim, J.; Waqas, A.; MiniRev. Org. Chem. 2013, 10, 73.
27. Deshpande, A. M.; Argade, N. P.; Natu, A. A.; Eckman, J.; Bioorg. Med. Chem. 1999, 7, 1237.

28. Sun, Y. F.; Cui, Y. P.; Dyes Pigm. 2009, 81, 27.

29. Wang, G-q.; Qin, J.-C.; Fan, L.; Li, C.-R.; Yang, Z.-Y.; J. Photochem. Photobiol., A 2016, 314, 29.

30. Lanke, S. K.; Sekar, N.; Dyes Pigm. 2016, 127, 116.

31. Qin, J.-c.; Yang, Z.-y.; Fan, L.; Wang, B.-d.; Spectrochim. Acta, Part A 2015, 140, 21.

32. Kasha, M.; Rawls, H. R.; El Bayoumi, M. A.; Pure Appl. Chem. 1965, 11, 371 .

33. Kasha, M.; Radiat. Res. 1963, 20, 55.

34. Frisch, M. J.; Trucks, G. W.; Schlegel, H. B.; Scuseria, G. E.; Robb, M. A.; Cheeseman, J. R.; Scalmani, G.; Barone, V.; Mennucci, B.; Petersson, G. A.; Nakatsuji, H.; Caricato, M.; Li, X.; Hratchian, H. P.; Izmaylov, A. F.; Bloino, J.; Zheng, G.; Sonnenberg, J. L.; Hada, M.; Ehara, M.; Toyota, K.; Fukuda, R.; Hasegawa, J.; Ishida, M.; Nakajima, T.; Honda, Y.; Kitao, O.; Nakai, H.; Vreven, T.; Montgomery Jr., J. A.; Peralta, J. E.; Ogliaro, F.; Bearpark, M.; Heyd, J. J.; Brothers, E.; Kudin, K. N.; Staroverov, V. N.; Kobayashi, R.; Normand, J.; Raghavachari, K.; Rendell, A.; Burant, J. C.; Iyengar, S. S.; Tomasi, J.; Cossi, M.; Rega, N.; Millam, J. M.; Klene, M.; Knox, J. E.; Cross, J. B.; Bakken, V.; Adamo, C.; Jaramillo, J.; Gomperts, R.; Stratmann, R. E.; Yazyev, O.; Austin, A. J.; Cammi, R.; Pomelli, C.; Ochterski, J. W.; Martin, R. L.; Morokuma, K.; Zakrzewski, V. G.; Voth, G. A.; Salvador, P.; Dannenberg, J. J.; Dapprich, S.; Daniels, A. D.; Farkas, Ö.; Foresman, J. B.; Ortiz, J. V.; Cioslowski, J.; Fox, D. J.; Gaussian 09, Revision C.01, Gaussian, Inc., Wallingford CT, 2009.

Submitted: August 9, 2017 Published online: December 4, 2017 